\title{
Effect of Mn on Ageing of Cu-Al-Ni-Mn-B Alloys
}

\author{
C. Seguí and E. Cesari
}

Dept. Física, Universitat de les Illes Balears, Campus Universitari, Ctra de Valldemossa, km. 7,5, E-07071 Palma de Mallorca, Spain

\begin{abstract}
The effect of post-quench ageing in the $\beta$-phase on the transformation characteristics of a set of $\mathrm{Cu}-\mathrm{Al}-\mathrm{Ni}$ alloys with $\mathrm{Mn}$ and $\mathrm{B}$ additions have been investigated by means of DSC and X-Ray diffraction. The observed behaviour show different stages which correspond to recovery of the order suppressed by quench and second phase precipitation.
\end{abstract}

\section{INTRODUCTION}

$\mathrm{Cu}-\mathrm{Al}-\mathrm{Ni}$ alloys are more stable at high temperatures than $\mathrm{Cu}-\mathrm{Zn}-\mathrm{Al}$ alloys, raising the upper temperature limit of operation for shape memory devices to about $200^{\circ} \mathrm{C}[1]$. Furthermore, they are claimed to be less prone to martensite stabilization. However, commercial use of $\mathrm{Cn}-\mathrm{Al}-\mathrm{Ni}$ has been strongly limited because of grain coarsening and precipitation of the brittle $\gamma_{2}$ phase. A common way to improve it is to replace partially Al content by Mn. Manganese remains in solution, increases the stability domain of the $\beta$ phase and hence allows heat treatments to be performed at lower betatising temperatures promoting the martensite formation at lower quenching rates [1]. On the other hand, decreasing $\mathrm{Al}$ content to below 14 wt\% suppresses $\gamma_{2}$ precipitation but raises the transformation temperatures, while Mn lowers them considerably. A fifth element such as Ti or B is usually added to assess grain refinement [2]. The resulting quinary alloys have significantly improved mechanical properties spreading over a wide temperature range, but they are far more complex than ternary $\mathrm{Cu}-\mathrm{Al}-\mathrm{Ni}$, and their ordering and ageing behaviour, as well as the kinetics of the subsequent martensitic transformation, are largely unknown.

The results obtained until now concerning quenched $\mathrm{Cu}-\mathrm{Al}-\mathrm{Ni}-\mathrm{Mn}-\mathrm{B}$ [3] and $\mathrm{Cu}-\mathrm{Al}-\mathrm{Ni}-\mathrm{Mn}-\mathrm{Ti}$ [4] alloys show that in most cases a quench from the $\beta$-stability region into martensite leads to overlaid suppression of the transformation temperatures due to quenched disorder and martensite stabilization. Ordering and removal of the martensite stabilization are attained upon ageing in $\beta$ phase which occurs during cycling itself, the first process being appreciably slower in kinetics than the last mentioned. Disorder and martensite stabilization have opposite effects on the transformation temperatures of the first reverse transformation after the quench, and the results show that the transformation temperature shifts due to each of the competitive processes are very much dependent on the temperature from which the quench is performed. It is also observed that $\mathrm{Mn}$ content strongly influences both ordering and stabilization kinetics.

The transformation temperature measured after a quench is therefore not stable, but it evolves during cycling and ageing. Post quench ageing treatments in $\beta$-phase below the ordering temperatures have the effect of releasing quenching stresses, annealing out the excess of vacancies and ordering the material, 
but at ageing temperatures as high as $200{ }^{\circ} \mathrm{C}$ other processes leading to decomposition of the $\beta$-phase are activated. Since decomposition proceeds through different paths depending on the alloy composition $[5,6]$, substitution of $\mathrm{Al}$ by $\mathrm{Mn}$ will affect the ageing behaviour of $\mathrm{Cu}-\mathrm{Al}-\mathrm{Ni}$ alloys through both the quench recovery and the decomposition path.

In the present work the effect of $\beta$-ageing on the martensitic transformation of several $\mathrm{Cu}-\mathrm{Al}-\mathrm{Ni}-\mathrm{Mn}-\mathrm{B}$ alloys, Mn at\% ranging between 0 and 4 , is presented.

\section{EXPERIMENTAL PROCEDURES}

Four alloys with composition given in Table I were used. All the studied alloys have nominal $\mathrm{A}_{\mathrm{S}} \approx 100^{\circ} \mathrm{C}$ and are fully in martensitic phase at room temperature. The previous heat treatment for all alloys consisted of annealing at $800^{\circ} \mathrm{C}$ for $20 \mathrm{~min}$. followed by quenching in water at room temperature. The samples were subsequently aged at different temperatures between 150 and $300{ }^{\circ} \mathrm{C}$ up to 5 hours. The ageing was performed inside a DSC in the following way: the as quenched samples were cycled at a temperature rate of $10 \mathrm{Kmin}^{-1}$ between room temperature and the ageing temperature, where they were kept for increasing time, the forward and reverse transformation which took place during cycling being recorded.

TABLE I.- Composition (in at\%) of the studied alloys.

\begin{tabular}{llllll}
\hline alloy & $\mathrm{Cu}$ & $\mathrm{Al}$ & $\mathrm{Ni}$ & $\mathrm{Mn}$ & $\mathrm{B}$ \\
\hline 1 & 70.2 & 24.9 & 2.9 & 2.0 & 0.15 \\
2 & 70.0 & 23.9 & 2.9 & 3.1 & 0.15 \\
3 & 70.6 & 22.9 & 2.7 & 3.7 & 0.13 \\
4 & 69.7 & 26.0 & 4.1 & 0 & 0.20 \\
\hline
\end{tabular}

The structure of both the martensite and the $\beta$ phases was analyzed using X-Ray diffraction in the asquenched and aged states. The $\beta$ structure was also studied on cooling from $800^{\circ} \mathrm{C}$ inside the $\mathrm{X}$-Ray chamber, and the phases present after $5 \mathrm{~min}$. at several temperatures down to $200^{\circ} \mathrm{C}$ were determined.

\section{RESULTS AND DISCUSSION}

In a previous work [3] the behaviour of the studied alloys after direct quench from a range of quenching temperatures into martensite was studied. It was shown that for the Mn containing alloys the first reverse transformation after water quench from above $400^{\circ} \mathrm{C}$ occurs at higher temperatures and it spreads over a broader temperature range than the following ones, while on quenching from below this temperature the first reverse transformation appears at lower temperatures than the following ones. On the other side, the alloy which does not contain Mn showed the first reverse transformation at lower temperatures than the following ones for all quenching temperatures. The latter behaviour can be interpreted in terms of the recovery upon $\beta$-ageing of quenched-in disorder, and in the case of the $\mathrm{Mn}$ containing alloys this mechanism is overlapped to martensite stabilization occurred during the quench which shifts up the first reverse transformation. Both the stabilization and the suppression shifts depend on the quenching temperature, causing one or the other effect to predominate. The described behaviour can be seen in Fig. 1 , which shows the difference between the peak temperatures of the first and second reverse transformations as measured by DSC as a function of the quenching temperature. It can be also observed there that the stabilization shift is higher the higher the Mn content, indicating that Mn enhances stabilization.

Figs. 2 to 5 show the reverse transformation peak temperature shift relative to the as-quenched state and the transformation hysteresis as a function of ageing time at different temperatures for alloys 1 to 4 respectively. According to the results of previous work, removal of the stabilization, which occurs in very short ageing time, causes a former and sharp decrease of tansformation temperatures for $\mathrm{Mn}$ containing alloys. The reverse transformation temperatures measured after slow cooling from $800{ }^{\circ} \mathrm{C}$ are also indicated in the figures. This temperature is taken as at reference since no shifts between the first and 
following reverse transformations are measured after slow cooling of none of the alloys, and both ordering and defects annealing are almost complete after slow cooling.

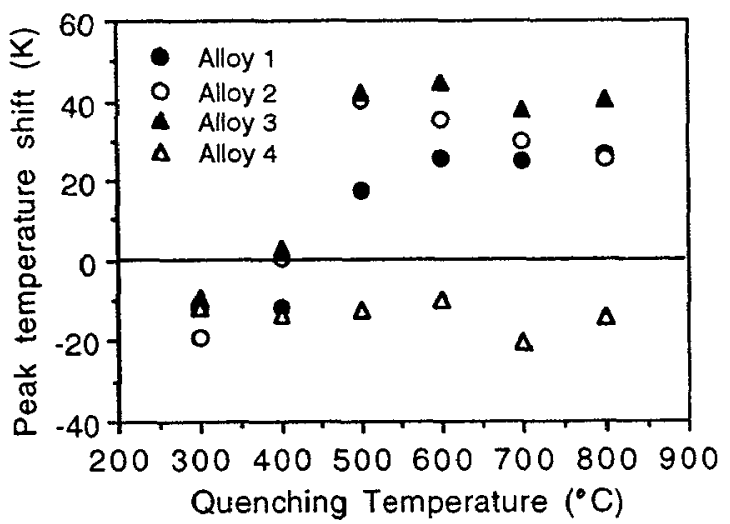

Fig. 1.-Difference between the peak temperatures of the first and second reverse transformations as measured by DSC as a function of the quenching temperature.
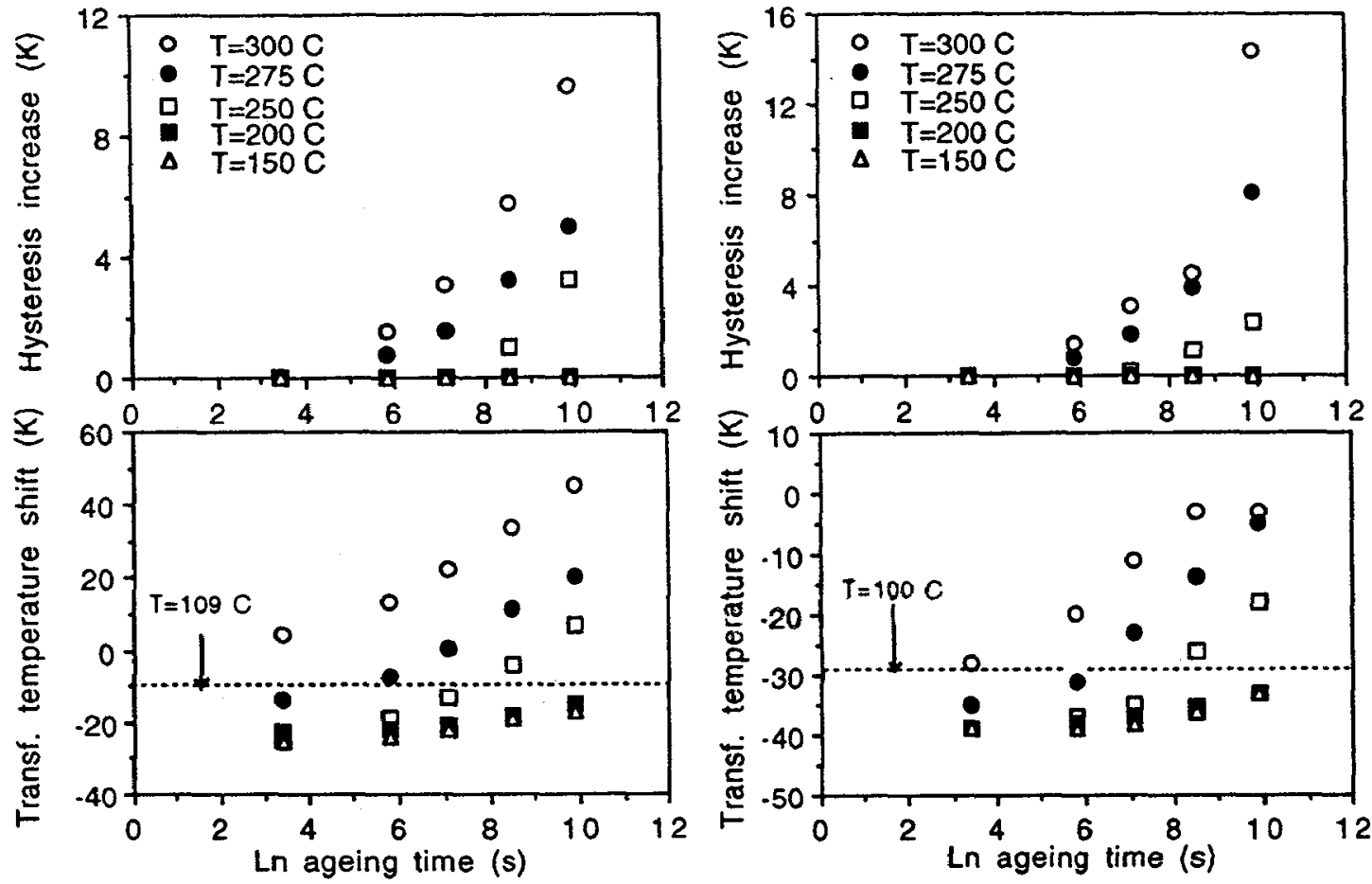

Figs. 2 (left) and 3 (right).- Reverse transformation peak temperature shift relative to the as-quenched state and the transformation hysteresis as a function of ageing time at different temperatures for alloys 1 (fig. 2) and 2 (fig. 3). The dotted lines indicate the reverse transformation temperatures measured after slow cooling from $800^{\circ} \mathrm{C}$.

It can be observed in the figures that in all cases the transformation temperatures increase with ageing time while the hysteresis width starts to increase after some time ageing at temperatures above $200^{\circ} \mathrm{C}$. However, several stages of ageing can be distinguished: 
(i) For ageing temperatures below $200^{\circ} \mathrm{C}$ all alloys show small increase of transformation temperatures without overcoming that corresponding to slow cooling. The hysteresis remains constant.

(ii) For ageing above $200^{\circ} \mathrm{C}$ and up to 1 hour ageing, a higher increase of transformation temperatures together with an increase of hysteresis is observed in all cases.

(iii) For longer ageing time and temperatures above $250^{\circ} \mathrm{C}$, alloy 1 maintains the above behaviour but distinctive features are observed for the other alloys: alloys 2 and 3 show, specially in the case of alloy 2, the beginning of a decrease of the transformation temperatures and a higher increase of hysteresis. Also both alloys show a decrease of about $20 \%$ in transformation enthalpy. Alloy 4 , on its turn, shows increase of the transformation temperatures and a marked increase in hysteresis, but the transformation enthalpy does not change.
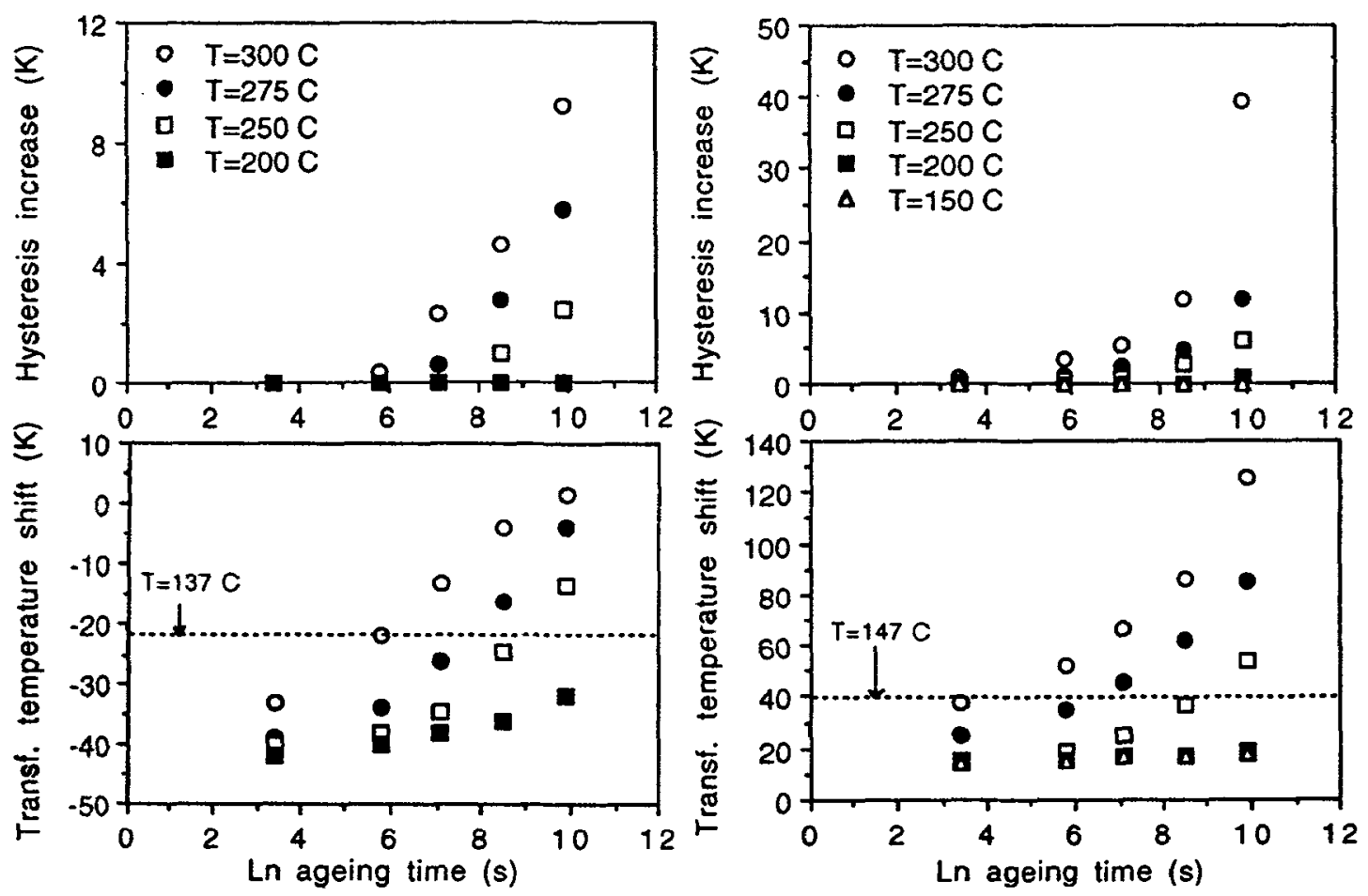

Figs. 4 (left) and 5 (right).- Reverse transformation peak temperature shift relative to the as-quenched state and the transformation hysteresis as a function of ageing time at different temperatures for alloys 3 (fig. 4) and 4 (fig. 5). The dotted lines indicate the reverse transformation temperatures measured after slow cooling from $800^{\circ} \mathrm{C}$.

$\mathrm{X}$-Ray diffraction revealed that all the studied alloys have $18 \mathrm{R}$ martensite structure at room temperature. On cooling from the $\beta$-stability region the ordering reactions disordered $\rightarrow$ B2 and B2 $\rightarrow$ L21 were observed for all alloys [3] and, in addition to the ordered $\beta$ phase, $\alpha$ phase was detected in alloys 2,3 and 4 below $550^{\circ} \mathrm{C}$, while $\gamma_{2}$ peaks were observed only in alloy 4 below $550^{\circ} \mathrm{C}$. Alloy 1 showed the peaks of the ordered $\mathrm{L} 2{ }_{1} \beta$ alone down to $200^{\circ} \mathrm{C}$. Specimens of all alloys aged in situ in the $\mathrm{X}$-Ray chamber up to 2 hours at $300^{\circ} \mathrm{C}$ did not show other phases than $\beta$ at this temperature, but severely aged (up to 15 hours) samples of alloy 4 showed traces of $\gamma_{2}$ while alloy 2 showed some $\alpha$ peaks. It is interesting to notice that in both cases transformation from $\beta$ to martensite took place even after this ageing time. Preliminary TEM studies of quenched and aged samples have been also performed and they indicate that $\gamma_{2}$ precipitates are already present in alloy 4 after 15 min. ageing at $300^{\circ} \mathrm{C}$, although their amount can be 
not enough to be detected by X-Ray diffraction. Alloys 1 and 2, on its turn, show $\gamma_{2}$ precipitates after prolonged ageing (about 20 hours) at $150-200^{\circ} \mathrm{C}$.

From the described results, the ageing stages can be interpreted as follows: recovery of second neighbors order suppressed during the quench causes temperature increase in the first stage [7], while precipitation of second phase particles is responsible for the latter stages of ageing [5,7,8]. A former decrease of transformation temperatures observed by several authors upon ageing $\mathrm{Cu}$ - $\mathrm{Al}$-Ni alloys [7,8], which they attributed to first neighbor reorder, has not been observed in the present alloys. Precipitation starts in stage (ii) causing a rise in hysteresis and becomes massive in stage (iii), although complete decomposition of none of the alloys occurs up to the maximum ageing time and temperatures attained in this study. The nature of the precipitated phases is still to be completely identified for the different alloys, but according to $X$-Ray diffraction results $\gamma_{2}$ seems to be likely formed in alloy 4 , the richest in $\mathrm{Al}$, which is also consistent with the preliminary TEM results. $\gamma_{2}$ precipitation causes Al depletion of the matrix and consequently an increase of transformation temperatures [5,7]. The behaviour displayed by alloys 2 and 3 has been attributed in the literature $[5,6]$ to bainite formation which lately becomes $\alpha$ phase. This is also in agreement with the presence of $\alpha$ phase in overaged alloy 2 , although occurrence of $\gamma_{2}$ precipitation during ageing stage (ii) can not be disregarded according TEM results. It is interesting to notice that the studied alloys show a quite good thermal resistance even at $300^{\circ} \mathrm{C}$, the most stable behaviour upon ageing being shown by alloy 1 .

\section{References}

[1] Van Humbeeck J. and Delaey L., "The martensitic tansformation in Science and Technology". Edited by E. Hornbogen and N. Jost (DGM, 1989) p. 15.

[2] Sugimoto K., Kamei K., Matsumoto H., Komatsu S. and Sugimoto T., J. de Physique 43 (1982) C4761.

[3] Seguí C. and Cesari, E. submitted to J. of Mat. Sci. (1994).

[4] Hurtado I., Van Humbeeck J. and Delaey L., J. de Physique 1 (1991) C4-247.

[5] Itsumi Y., Miyamoto Y., Takashima T., Kamei K. and Sugimoto K., Mat. Sci. Forum, $56-58$ (1990) 469.

[6] Dutkievicz J., Cesari E., Seguí C. and Pons J., J. de Physique 43 (1992) C4-761.

[7] Van Humbeeck J., Chandrasekaran, M. and Delaey L., ISIJ Intemational 29 (1989) 388.

[8] Rodriguez P. and Guénin G., Mater. Sci. and Eng. A 129 (1990) 273.

\section{Acknowledgments}

This work has received financial support from DGICYT PB90-0039 and CICYT MAT93-0188. The authors are indebted to J. Pons for his help in TEM observations. 